\title{
The contribution of mortality statistics to the study of multiple sclerosis in Australia
}

\author{
S R HAMMOND,* D R ENGLISH, $\dagger$ C de WYTT, $\ddagger$ J F HALLPIKE,§ K S MILLINGEN, $\|$ \\ E G STEWART-WYNNE, J J MCLEOD,* M G MCCALL**
}

From the Departments of Medicine: University of Sydney* and University of Tasmania; $\|$ NH and MRC

Research Unit in Epidemiology and Preventive Medicine, Perth; $\dagger$ Departments of Neurology: Greenslopes

Repatriation Hospital, Brisbane, $\ddagger$ Royal Adelaide Hospital, Adelaide, $\S$ Royal Perth Hospital, Perth; $\uparrow$

Department of Extended Care, Sir Charles Gairdner Hospital, Perth, ${ }^{* *}$ Australia

SUMMARY Mortality statistics provided a valuable source of support for data obtained from prevalence surveys of multiple sclerosis in Australia. Firstly, multiple sclerosis mortality data for the decade 1971-80 in the States of Australia confirmed the relationship between increasing disease frequency and increasing south latitude shown by State and regional point prevalence surveys based on the national census day 30 June 1981 . Secondly, a comparison with mortality data from the decade 1950-59 showed that in most States there had been a substantial fall in multiple sclerosis mortality in the more recent decade and this was clearly an important contributing factor to the rise in prevalence noted between the morbidity surveys of 1961 and 1981. Thirdly, multiple sclerosis mortality in the UK-born migrant population dying in Australia was found to be similar to that of the Australianborn population and very much lower than that found in the UK. This observation corroborated evidence from the 1981 morbidity surveys and suggested that migration from the UK to Australia may lower the risk of developing multiple sclerosis either through a reduction in disease incidence or the operation of environmental factors curbing disease expression.

Mortality statistics have provided important insights into the epidemiology of multiple sclerosis, despite the potential inaccuracies of such data. ${ }^{1-5}$ The first clear demonstration of the relationship between geographical latitude and multiple sclerosis frequency was made with mortality statistics, ${ }^{6}$ and they have also been helpful in studying temporal trends in multiple sclerosis frequency. ${ }^{37-9}$

In Australia, the first epidemiological study of multiple sclerosis was based on mortality data: Acheson ${ }^{10}$ found that mortality over the decade 1950 59 in the six States showed a close relationship with latitude with the notable exception of Queensland (QLD), whilst no such relationship was found for mortality from motor neuron disease (MND) over the same time period. His study also showed that mortality from multiple sclerosis in Australia was considerably lower than that in the United Kingdom

Address for reprint requests: Dr S R Hammond, Department of Medicine, University of Sydney, Sydney, NSW 2006, Australia.

Received 8 July 1988 and in revised form 7 September 1988. Accepted 12 September 1988
(UK) measured over the triennium 1954-56, whilst mortality from MND was much the same in the two countries.

Recent State and regional multiple sclerosis prevalence surveys in Australia ${ }^{11} 12$ have also shown a strong association between disease frequency and latitude, with multiple sclerosis frequency increasing about fourfold in a southerly direction across the continent. Furthermore, multiple sclerosis prevalence in English-born migrants was found to be considerably lower than that found recently in England ${ }^{1314}$ in all except the southernmost areas of Australia.

The principal aims of this study were firstly, to see if the findings of the recent multiple sclerosis prevalence surveys in Australia were supported by mortality statistics for the decade 1971-80 prior to the surveys, and secondly, to make a comparison between these mortality data and those obtained by Acheson. ${ }^{10}$ Finally, the reliability of such mortality data in estimating the frequency of multiple sclerosis in Australia was assessed by a comparison with data on deaths among known multiple sclerosis patients in the State of New South Wales (NSW). 


\section{Methods}

Epidemiological surveys of multiple sclerosis were conducted in five areas of Australia: the States of QLD, Western Australia (WA) and South Australia (SA), the statistical division of Hobart in the State of Tasmania (TAS) and the statistical district of Newcastle in the State of NSW. For all areas the prevalence day was the national census day 30 June 1981. The methods of case ascertainment for the surveys were similar in all areas and have been fully described elsewhere. ${ }^{112}$ Standardisation of procedures was ensured by regular meetings of survey co-ordinators from each area.

Mortality data for multiple sclerosis in the decade 1971-80 were supplied for the States and Territories of Australia by the Australian Bureau of Statistics (ABS); similar data for the countries of the UK for the triennium 1974-76 were obtained through the ABS. In each case, the data consisted of only those patients in whom multiple sclerosis was stated as the underlying cause of death (UCD). Average mortality rates were expressed per 100,000 person years, the denominators in Australia being the census populations at 30 June 1976 in each area, and in the UK the 1975 mid-year population estimates in each country.

The ABS also supplied mortality data for multiple sclerosis in the decade 1971-80 for the whole country of Australia according to birthplace in Australia or in the UK. Denominator populations enabling calculation of separate mortality rates for these two populations were obtained directly from the national census of 30 June 1976.

For the purpose of examining the relationship between multiple sclerosis mortality and latitude, a mean latitude was calculated for each State of Australia from the population distributions in their respective statistical divisions at the 1976 census. Similarly, for the prevalence data, mean latitudes in the States of QLD, WA and SA were calculated from their population distributions at the 1981 census.

In NSW, the ABS provided the death certificate numbers of all patients in whom multiple sclerosis was coded as the UCD in the period 1976 to 1985 inclusive. These certificates and those of multiple sclerosis patients not included in the ABS data who were known from the NSW prevalence survey to have died in this time interval were examined by one of us (SRH) with the permission of the Registrar of Births, Deaths and Marriages.

\section{Statistics}

Prevalence in 1981 and mortality rates for the decade 197180 in Australia were age-standardised to the 1981 Australian population. In addition, prevalence and mortality ratios and their respective $95 \%$ confidence intervals were calculated from a Poisson regression model in which the number of cases was considered to be the (Poisson) response variable, and the population size was declared to be an offset term. ${ }^{15}$ Prevalence and mortality were modelled as a function of age (grouped in six categories 20-29, 30-39, 40-49, 50-59, 60-69, $70+$; the age group 0-19 was not included as no deaths occurred among people less than 20 years old) and place of residence in Australia. Trends in prevalence and mortality by latitude of residence in Australia were examined by including a single linear term for latitude in the regression model, this function predicting that multiple sclerosis prevalence and mortality increased exponentially with increasing south latitude. Differences between the respective relationships of multiple sclerosis prevalence and mortality with latitude were tested by adding an interaction term of outcome (that is, mortality or prevalence) by latitude.

Mortality rates for the decade 1971-80 in Australia and the triennium 1974-76 in the UK were also age-standardised to the 1950 US population to facilitate comparisons with Acheson's ${ }^{10}$ data. Acheson's ${ }^{10}$ report did not contain agespecific rates or variances of age-standardised rates; therefore, statistical comparisons between rates presented in that paper and those calculated from the present data were made by assuming the number of deaths in the population followed a Poisson distribution. Using this assumption, the variance of the $\log$ of the ratio of two rates is given by the formula $1 / 0_{1}+1 / 0_{2}$ where $0_{1}$ and $0_{2}$ are the numbers of deaths in the two populations under comparison. ${ }^{16}$ For large samples, the log of the rate ratio (RR) is approximately normally distributed and thus calculation of its $95 \%$ confidence interval was based on the normal approximation. Statistical comparisons between age-standardised mortality rates calculated from the present data were made with the method described by Knowler et al ${ }^{17}$ and have also been expressed as RRs with their $95 \%$ confidence intervals.

\section{Results}

Temporal trends in multiple sclerosis mortality:

(a) Australia - the decades 1950-59 and 1971-80 Table 1 shows that the age-standardised mortality of multiple sclerosis in Australia had declined in each State in the more recent decade with the exception of WA where multiple sclerosis mortality had remained essentially stable. The falls in mortality were greater than could be explained by chance in Australia as a whole $(28 \%, p<0.0001)$ and in the States of QLD $(53 \%, \mathrm{p}<0.0001)$, NSW $(31 \%, \mathrm{p}<0.001)$ and Victoria $(23 \%, p<0.004)$ but not in SA $(13 \%$, $p>0.42)$ or Tas $(34 \%, p>0.07)$.

Table 1 Comparison between multiple sclerosis mortality in the decades 1950 to 1959 and 1971 to 1980 in Australia

\begin{tabular}{|c|c|c|c|c|c|c|}
\hline \multirow[b]{2}{*}{ State } & \multicolumn{2}{|c|}{$1950-1959^{*}$} & \multicolumn{2}{|c|}{$1971-1980+$} & \multirow{2}{*}{$\begin{array}{l}\text { Rate } \\
\text { ratio }\end{array}$} & \multirow[b]{2}{*}{$95 \% C I$} \\
\hline & Deaths & Mort. & Deaths & Mort. & & \\
\hline $\begin{array}{l}\text { Queensland } \\
\text { Western Australia } \\
\text { New South Wales } \\
\text { South Australia } \\
\text { Victoria } \\
\text { Tasmania }\end{array}$ & $\begin{array}{r}94 \\
22 \\
223 \\
52 \\
237 \\
35\end{array}$ & $\begin{array}{l}0 \cdot 76 \\
0 \cdot 37 \\
0 \cdot 65 \\
0 \cdot 67 \\
0 \cdot 96 \\
1 \cdot 25\end{array}$ & $\begin{array}{r}71 \\
40 \\
222 \\
72 \\
267 \\
32\end{array}$ & $\begin{array}{l}0 \cdot 36 \\
0 \cdot 39 \\
0 \cdot 45 \\
0 \cdot 58 \\
0 \cdot 74 \\
0 \cdot 82\end{array}$ & $\begin{array}{l}0.47 \\
1.05 \\
0.69 \\
0.87 \\
0.77 \\
0.66\end{array}$ & $\begin{array}{l}0.35-0.64 \\
0.63-1.77 \\
0.57-0.83 \\
0.61-1.24 \\
0.65-0.92 \\
0.41-1.07\end{array}$ \\
\hline Australia & 663 & 0.74 & $713 \ddagger$ & 0.53 & 0.72 & $0.65-0.80$ \\
\hline
\end{tabular}

Abbreviations: Mort. $=$ Mortality per 100,000 person years adjusted to the age distribution of the 1950 US population; $\mathrm{CI}=$ confidence interval.

* - data obtained from Acheson (1961).

- data obtained from the Australian Bureau of Statistics.

7 -this figure includes 9 deaths from the Territories 7 from the Australian Capital Territory and 2 from the Northern Territory); there were no recorded deaths from multiple sclerosis in either territory in the earlier decade. 
(b) United Kingdom-the triennia 1954-56 and 1974-76

Table 2 shows that the age-standardised mortality of multiple sclerosis in the UK had declined by $19 \%$ $(p<0.0001)$ in the more recent triennium. This trend was seen in each of its constituent countries, the falls all being greater than could be explained by chance (Scotland 42\%,p < 0.0001; England and Wales 14\%, p $<0.0001$; Northern Ireland 25\%, p < 0.03).

Table 2 Comparison between multiple sclerosis mortality in the triennia 1954 to 1956 and 1974 to 1976 in the United Kingdom

\begin{tabular}{|c|c|c|c|c|c|c|}
\hline \multirow[b]{2}{*}{ Country } & \multicolumn{2}{|c|}{$1954-1956^{*}$} & \multicolumn{2}{|c|}{$1974-1976+$} & \multirow{2}{*}{$\begin{array}{l}\text { Rate } \\
\text { ratio }\end{array}$} & \multirow[b]{2}{*}{$95 \% C I$} \\
\hline & Deaths & s Mort. & Deaths & s Mort. & & \\
\hline $\begin{array}{l}\text { Scotland } \\
\text { Northern Ireland } \\
\text { England \& Wales }\end{array}$ & $\begin{array}{r}488 \\
128 \\
2453\end{array}$ & $\begin{array}{l}2.93 \\
3 \cdot 14 \\
1 \cdot 60\end{array}$ & $\begin{array}{r}305 \\
110 \\
2404\end{array}$ & $\begin{array}{l}1 \cdot 70 \\
2 \cdot 34 \\
1 \cdot 37\end{array}$ & $\begin{array}{l}0.58 \\
0.75 \\
0.86\end{array}$ & $\begin{array}{l}0.50-0.67 \\
0.58-0.97 \\
0.81-0.91\end{array}$ \\
\hline United Kingdom & 3069 & $1 \cdot 77$ & 2819 & 1.43 & 0.81 & $0.77-0.85$ \\
\hline
\end{tabular}

Abbreviations: Mort. $=$ Mortality per 100,000 person years adjusted to the age distribution of the 1950 US population; CI = confidence interval.

- data obtained from Acheson (1961)

$\dagger$-data obtained from the Australian Bureau of Statistics.
Comparison of multiple sclerosis mortality in the United Kingdom and Australia

In both time periods of comparison, the age-standardised mortality from multiple sclerosis was substantially higher in the UK (table 2) than in Australia (table 1) (first period: RR 2.39, 95\% CI 2.20-2.60, p < 0.0001; second period: RR $2.70,95 \%$ CI 2.50 $2.92, \mathrm{p}<0.0001)$. Age-specific mortality in the more recent time period of comparison showed a monophasic pattern in both countries (fig. 1), peaking around the sixth to seventh decades of life with a decline thereafter; the peak for females and all persons was slightly later in Australia than in the UK. An excess of females was also apparent in both countries, the female:male ratios being 1.9:1 and 1.6:1 in Australia and the UK respectively, the figure for Australia being similar to that found in the five 1981 regional prevalence surveys combined (2:4:1).

Of the 713 deaths from multiple sclerosis in Australia from 1971-80, $561(79 \%)$ subjects were born in Australia and $72(10 \%)$ in the UK. Age-standardised (1950 US population) mortality was 0.57 in the Australian-born population and 0.44 in the UK-born population, a difference just exceeding that which could be explained by chance (RR $1 \cdot 30,95 \%$ CI $1 \cdot 01-$ $1.67, \mathrm{p}<0.05$ ). However, the difference in age-
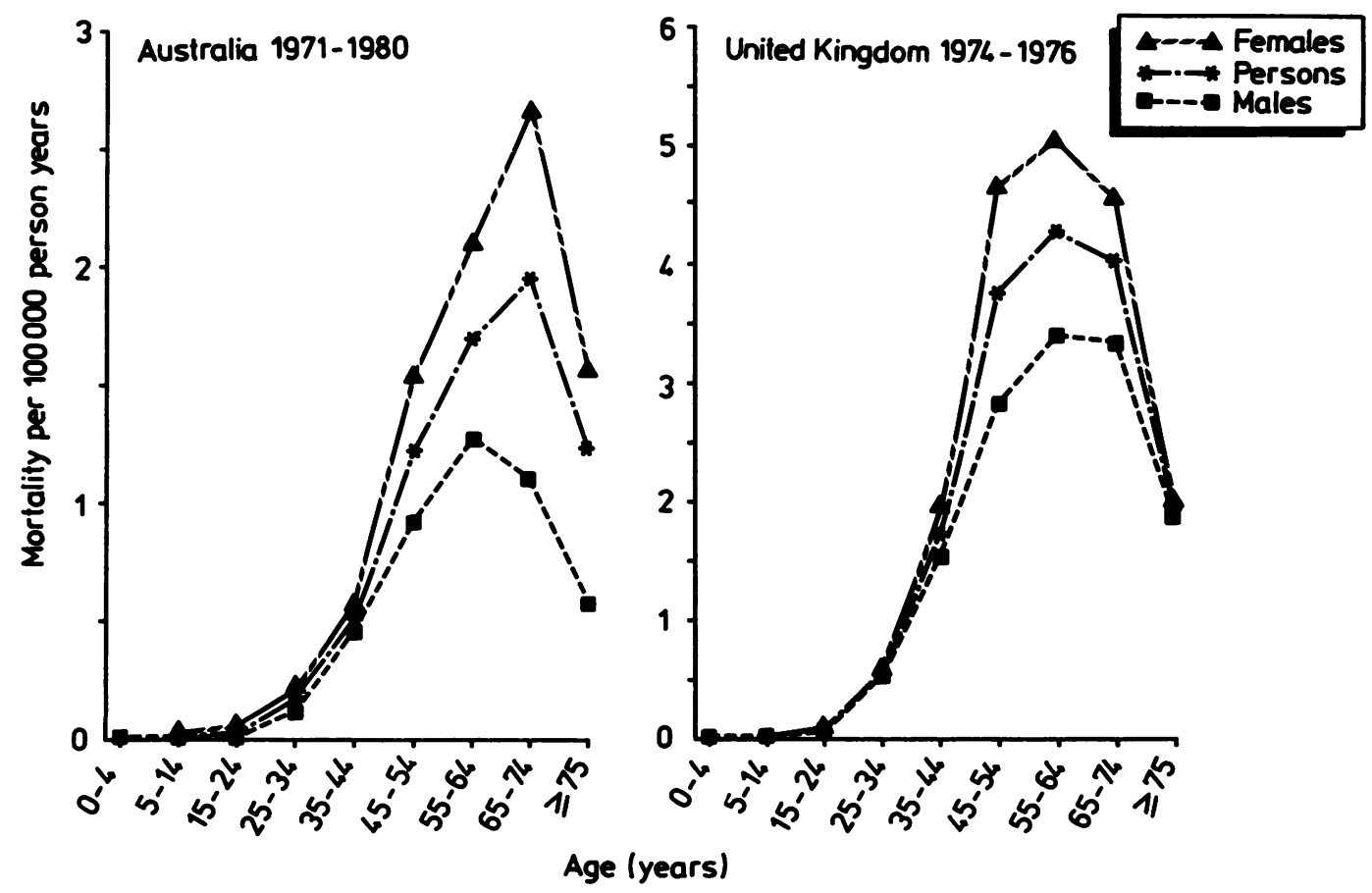

Fig 1 Age-specific mortality per 100,000 person years in the decade 1971 to 1980 in Australia and the triennium 1974 to 1976 in the United Kingdom. 
standardised mortality between the UK-born population in Australia and that of their non-migrating compatriots was very large ( $R R 3.25,95 \%$ CI $2 \cdot 56$ $4 \cdot 12, \mathrm{p}<0.0001)$.

Multiple sclerosis mortality and morbidity in Australia in relation to latitude

The five 1981 multiple sclerosis prevalence surveys showed clearly that there was an overall relationship between increasing multiple sclerosis frequency and increasing south latitude $(p<0.001)$ (table 3$)$. However, there was an inconsistency within this gradient in that the age-standardised prevalence of multiple sclerosis in SA (1981 population: $1,285,032)$ was somewhat lower than that of the more northerly situated Newcastle statistical district (1981 population: 389,235 ) (RR 0.80, 95\% CI 0.66-0.97, p < 0.03). The figures for multiple sclerosis mortality in the six States of Australia in the decade 1971-80 (table 3; fig 2) confirmed ( $p<0.001)$ and extended the multiple sclerosis frequency gradient with latitude shown by the 1981 prevalence surveys with, moreover, no evidence of anomalies. The associations between latitude and multiple sclerosis prevalence and mortality were both modelled well by a single linear term for latitude. Furthermore, the test for interaction (that is, for differences in the relationship with latitude shown by the prevalence and mortality data) gave $p=0.39$, suggesting that any differences in the observed trends of mortality and prevalence with latitude could easily have been due to chance alone.
Table 3 Multiple sclerosis mortality per 100,000 person years in the decade 1971 to 1980 and multiple sclerosis prevalence per 100,000 of population in 1981 within Australia in relation to latitude

\begin{tabular}{|c|c|c|c|c|c|}
\hline Area & Lat. ${ }^{\circ} S$ & Pts. & Rate $^{*}$ & $\begin{array}{l}\text { Rate } \\
\text { ratioł }\end{array}$ & $95 \% C I$ \\
\hline $\begin{array}{l}\text { Mortality 1971-80 } \\
\text { Queensland } \\
\text { Western Australia } \\
\text { New South Wales } \\
\text { South Australia } \\
\text { Victoria } \\
\text { Tasmania } \\
\text { Prevalence 1981 } \\
\text { Queensland } \\
\text { Western Australia } \\
\text { Newcastle SDi } \\
\text { South Australia } \\
\text { Hobart SD }\end{array}$ & $\begin{array}{l}25 \cdot 1 \\
31.4 \\
33.6 \\
34 \cdot 8 \\
37 \cdot 6 \\
42.0 \\
\\
25 \cdot 1 \\
31 \cdot 3 \\
32.9 \\
34.9 \\
42.8\end{array}$ & $\begin{array}{r}71 \\
40 \\
222 \\
72 \\
267 \\
32\end{array}$ & $\begin{array}{l}0.36 \\
0.39 \\
0.46 \\
0.59 \\
0.75 \\
0.81\end{array}$ & $\begin{array}{l}1.00 \\
1.08 \\
1.30 \\
1.64 \\
2.12 \\
2.36 \\
1.00 \\
1.56 \\
2.13 \\
1.76 \\
4.58\end{array}$ & $\begin{array}{l}0.73-1.59 \\
0.99-1.69 \\
1.18-2.27 \\
1.63-2.75 \\
1.56-3.59\end{array}$ \\
\hline
\end{tabular}

Abbreviations: Lat. $^{\circ} \mathrm{S}=$ mean south latitude; $\mathrm{CI}=$ confidence interval; $\mathbf{S D}=$ statistical division; $\mathbf{S D i}=$ statistical district.

* = adjusted to the age distribution of the 1981 Australian population.

$\dagger=$ adjusted for age in a Poisson regression model.

Death certification of multiple sclerosis in the State of $N S W$

In the decade 1976 to 1985 , ABS data listed 230 deaths in NSW with multiple sclerosis as the UCD (UCD group); on reviewing the evidence for a diagnosis of multiple sclerosis in these cases, three $(0.01 \%)$ were rejected on the grounds of incorrect diagnosis. During this time period, a further 95 deaths not listed by the ABS occurred among multiple sclerosis patients

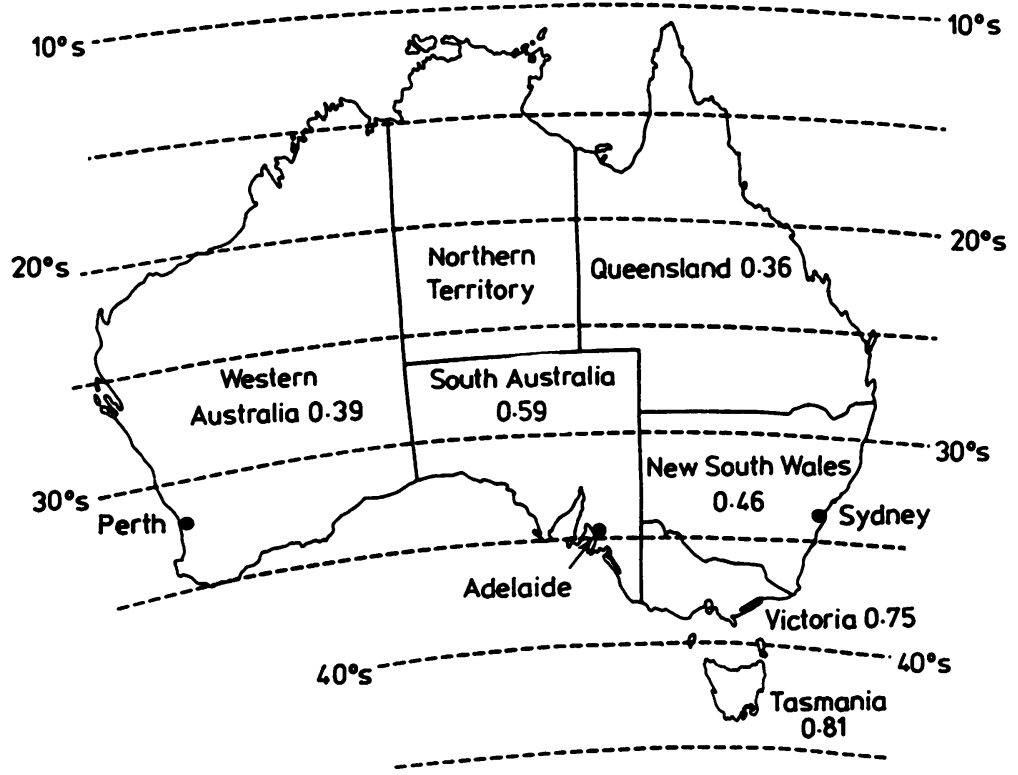

Fig 2 Map of Australia showing age-standardised (1981 Australian population) multiple sclerosis mortality in the decade 1971-80 in the six States of Australia. 
known to the NSW prevalence survey (non-UCD group); of these, $64(67 \%)$ had multiple sclerosis listed as a contributing cause of death (CCD) whilst in the remaining $31(33 \%)$ multiple sclerosis did not appear on the death certificate. As a measure of prevalence of multiple sclerosis at death in that time interval, therefore, the official mortality statistics in NSW provided an underestimate of $29 \%$ (ABS listed deaths [230]/total multiple sclerosis deaths [322]) or $30 \%$ if the three rejected cases are excluded. Even if all causes of death had been coded on death certificates, $10 \%$ of deaths $(31 / 322)$ in multiple sclerosis patients would still have been missed.

\section{Discussion}

Mortality statistics in most countries, including Australia, include only those deaths in which multiple sclerosis has been coded as the UCD in their cause-ofdeath statistics. Studies based solely on this source of information will, therefore, underestimate the frequency of multiple sclerosis at death. This is exemplified by the study of multiple sclerosis death certification in NSW. The prevalence of multiple sclerosis at death was underestimated by at least onequarter in NSW. Furthermore, one-tenth of deaths in multiple sclerosis patients in NSW had no mention of multiple sclerosis on their death certificates and these would have been missed even with multiple-causecoding. Other studies have shown similar trends: the proportion of multiple sclerosis deaths in which multiple sclerosis was not coded as the UCD varied from $18 \%{ }^{18}$ to $55 \%,{ }^{19}$ and with no mention of multiple sclerosis at all on the death certificate from $10 \%$ to $26 \% .^{19}$

In Australia, however, it is unlikely that in recent times there would have been any major interstate differences in the extent to which such mortality statistics underestimate the frequency of multiple sclerosis because medical services are similar in all States and of a uniformly high standard. Certainly, the striking gradient of disease frequency with latitude shown by mortality statistics for the decade 1971-80 (table 3; fig 2) seems unlikely to be artifactual for a number of reasons. Firstly, it confirms Acheson's ${ }^{10}$ finding of two decades previously; moreover, in the present study, QLD also conformed to the pattern. Secondly, it is unlikely that the gradient could be explained by any major interstate differences in the case-fatality ratio; indeed, the 1981 morbidity studies suggested that the disease may actually run a more malignant course in the hotter northerly regions of Australia $^{20}$ rather than the reverse. Thirdly, and perhaps most importantly, it is clearly consistent with and very similar to the gradient shown by the 1981 prevalence surveys. ${ }^{11}{ }^{12} \mathrm{~A}$ similar consistency between prevalence and mortality data in relation to multiple sclerosis frequency variations with latitude has recently been shown in neighbouring New Zealand ${ }^{21} 22$ and in the USA. ${ }^{5}$

The minor inconsistency in the multiple sclerosis frequency gradient with latitude shown by the 1981 prevalence surveys in Australia was most probably related to the differing sizes of the populations surveyed because case ascertainment is generally more complete with smaller population surveys. ${ }^{212} 23$ Indeed, the latter observation constitutes a possible source of criticism of the overall strength of the association between multiple sclerosis prevalence and latitude within Australia; this is particularly true of its extremes because the QLD population surveyed in $1981(2,295,122)$ was considerably larger than that of the Hobart statistical division $(168,363)$. The fact that the multiple sclerosis mortality figures confirmed this frequency gradient is, therefore, of considerable importance because its data collection was entirely independent of the prevalence surveys. Furthermore, the mortality gradient with latitude showed no anomalies and it extended the association to include areas where we were unable to get prevalence data. Although the multiple sclerosis frequency gradient with latitude is thought to be partly due to genetic factors in some countries, ${ }^{922}$ there is no convincing evidence that this is the case in Australia, ${ }^{12}$ thus arguing strongly for the existence of an important environmental factor in the aetiology of multiple sclerosis.

Mortality rates of multiple sclerosis in the decade 1971-80 had declined substantially in most States of Australia in comparison with the decade 1950-59 (table 1). This decline was reflected by a considerable increase in the age-specific prevalence of patients in the seventh decade of life and beyond between the 1961 and 1981 prevalence surveys. ${ }^{12}$ The fact that WA also showed this increase ${ }^{25}$ suggests that its mortality figure for the decade 1950-59 may have been a comparative underestimate. This occurrence could have resulted from differences between WA and other States at that time such as its lack of an established branch of the Multiple Sclerosis Society before 1960, or, less likely, a greater tendency among WA medical practitioners to code multiple sclerosis as a CCD.

In the decade 1950-59, the Australian age-specific multiple sclerosis mortality curves were biphasic in both sexes with initial peaks around 60 and 50 years of age in males and females respectively, followed in each case by a slight fall and then a second steep rise in old age; in contrast, the curves for England and Wales (1954-56), and New Zealand (1950-59) were clearly monophasic. Acheson ${ }^{10}$ suggested that the most likely explanation for this difference was a continuing tendency in Australia at that time to incorrectly code the 
terms "cerebral sclerosis" and "general sclerosis" as multiple sclerosis rather than as arteriosclerosis. However, the Australian age-specific curves for the decade 1971-80 were clearly monophasic and much closer approximations of the patterns shown by the United Kingdom in the triennium 1974-76 (fig 1) than in the earlier time periods of comparison. This finding supports Acheson's ${ }^{10}$ hypothesis and suggests that while the majority of the fall in the multiple sclerosis mortality rate in Australia in the more recent decade almost certainly was due to a genuine decline in mortality, part at least was due to resolution of this nosological confusion.

Over much the same time period, mortality from multiple sclerosis in the countries of the UK had also fallen substantially (table 2). ${ }^{89}$ However, the considerable difference between multiple sclerosis in the UK and Australia noted by Acheson ${ }^{10}$ was still apparent in the present study. More importantly, Acheson' ${ }^{26}$ further observation that mortality from multiple sclerosis in UK migrants dying in Australia (1957-61) was slightly lower after age-standardisation than that of the Australian-born population and very much lower than that of the native UK population, was also confirmed in the present study. One possible explanation for this finding is that the migrant population from the UK was preselected to exclude those people with established multiple sclerosis. However, as Acheson $^{26}$ himself commented, it seems questionable that differences of this magnitude could be entirely explained by preselection. In this regard, it is also interesting to note that $26 \%$ of all UK-born patients in the 1981 Australian multiple sclerosis prevalence surveys experienced disease onset prior to migration (Hammond et al, unpublished observations). Hence, when taken in conjunction with the findings among English-born migrants in the 1981 prevalence surveys, ${ }^{11}{ }^{12}$ a further, and perhaps more likely, explanation for this discrepancy is that migration from the UK to all but the southermost parts of Australia may lower the risk of developing multiple sclerosis either through a reduction in disease incidence or the operation of environmental factors curbing disease expression.

Kurtzke has stressed the importance of seeking "support from other approaches for any conclusions or inferences attained in any epidemiologic work". ${ }^{27}$ It seems clear from the present study and from recent studies in the $\mathrm{USA}^{s}$ and New Zealand ${ }^{22}$ that, in multiple sclerosis at least, mortality statistics may provide a valuable source of support for data obtained from prevalence surveys.

This study was supported by the National Multiple Sclerosis Society of Australia and the Bushell Trust. We are indebted to Professor J F Kurtzke for his invaluable advice in the planning of the Australian multiple sclerosis epidemiological study, and to $\mathrm{Mr} \mathrm{S}$ Bull and Mr L Coleman of the Australian Bureau of Statistics for their assistance with the gathering of the mortality data.

\section{References}

1 Stazio A, Kurland LT, Bell LG, Saunders MG, Rogot E. Multiple sclerosis in Winnipeg, Manitoba: methodological considerations of epidemiologic survey. Ten year follow-up of a community wide study, and population re-survey. J Chron Dis 1964;17:415-38.

2 Kurland LT, Stazio A, Reed D. An appraisal of population studies of multiple sclerosis. Ann NY Acad Sci 1965;122:520-44.

3 Massey EW, Schoenberg BS. International patterns of mortality from multiple sclerosis. Neuroepidemiology 1982;1:189-96.

4 Malmgren RM, Valdiviezo NL, Visscher BR, et al. Underlying cause of death as recorded for multiple sclerosis patients: associated factors. J Chron Dis 1983;36:699-705.

5 Kurtzke JF, Lux WE. In defense of death data: an example with multiple sclerosis. Neurology 1985;35:1787-90.

6 Limburg CC. The geographic distribution of multiple sclerosis and its estimated prevalence in the United States. Proc Assoc Res Nerv Ment Dis 1950;28:15-24.

7 Larsen JP, Kvale G, Aarli JA. Multiple sclerosis and mortality statistics. Acta Neurol Scand 1985;71:237-41.

8 Li T-M, Swash M, Alberman E. Morbidity and mortality in motor neuron disease: comparison with multiple sclerosis and Parkinson's disease: age and sex specific rates and cohort analyses. $J$ Neurol Neurosurg Psychiatry 1985;48:320-7.

9 Swingler RJ, Compston DAS. The distribution of multiple sclerosis in the United Kingdom. J Neurol Neurosurg Psychiatry 1986;49:1115-24.

10 Acheson ED. Multiple sclerosis in British Commonwealth countries in the southern hemisphere. Br J Preventive and Social Medicine 1961;15:118-25.

11 Hammond SR, de Wytt C, Maxwell IC, et al. The epidemiology of multiple sclerosis in Queensland, Australia. J Neurol Sci 1987;80:185-204.

12 Hammond SR, McLeod JG, Millingen KS, et al. The epidemiology of multiple sclerosis in three Australian cities: Perth, Newcastle and Hobart. Brain 1988;111:1-25.

13 McCoubrie M, Shuttleworth D. Prevalence of multiple sclerosis in West Yorkshire. Br Med J 1978;2:570.

14 Williams ES, McKeran RO. Prevalence of multiple sclerosis in a south London borough. $\mathrm{Br}$ Med J 1986;293:237-9.

15 Frome EL. The analysis of rates using Poisson regression models. Biometrics 1983;39:665-74.

16 Rothman KJ. Modern Epidemiology. Boston: Little, Brown, 1986:170-1.

17 Knowler WC, Bennett PH, Hamman RF, Miller M. Diabetes incidence and prevalence in Pima indians; a 19 fold greater incidence than in Rochester, Minnesota. Am J Epidemiol 1978;108:497-505.

18 Dassel H. The mortality from multiple sclerosis in the Netherlands. Acta Neurol Scand 1973;49:659-74.

19 O'Malley F, Dean G, Elian M. Multiple sclerosis and motor neurone disease: survival and how certified after death. $J$ Epidemiol Comm Health 1987;41:14-17.

20 Hammond SR, English D, de Wytt C, et al. The clinical profile of MS in Australia: a comparison between medium- and highfrequency prevalence zones. Neurology 1988;38:980-6.

21 Skegg DCG, Corwin PA, Craven RS, Malloch JA, Pollock M. Occurrence of multiple sclerosis in the north and south of New Zealand. J Neurol Neurosurg Psychiatry 1987;50:134-9.

22 Fawcett J, Skegg DCG. Geographic distribution of multiple 
sclerosis in New Zealand: evidence from hospital admissions and deaths. Neurology 1988;38:416-8.

23 Acheson ED. The epidemiology of multiple sclerosis. In: Matthews WB, ed. McAlpine's Multiple Sclerosis. Edinburgh: Churchill Livingstone, 1985:3-46.

24 Ebers GC, Bulman D. The geography of MS reflects genetic susceptibility. Neurology 1986;36, Suppl 1:108.
25 Hammond SR, Stewart-Wynne EG, English D, McLeod JG, McCall MG. The epidemiology of multiple sclerosis in Western Australia. Aust NZ J Med 1988;18:102-10.

26 Acheson ED. The geography of multiple sclerosis. Med J Aust 1963;1:556-7.

27 Kurtzke JF, Kurland LT, Goldberg ID. Mortality and migration in multiple sclerosis. Neurology 1971;21:1186-97.

\section{Chekhov: playwright and physician.}

A sketch of the brief medical career of Anton Pavlovich Chekhov (1860-1904) may be of passing interest. Son of a Taganrog grocer and grandson of a serf who had to buy his freedom, he was sent to read Medicine in Moscow, qualifying in 1884.

Under the nom-de-plume Antosha Chekhonte his literary talent surfaced in cheap and allegedly slightly pornographic and cheap magazines, whilst still a student. He practised Medicine, full-time at first, then moved to Melikhovo, outside Moscow and writing gradually became his prime work. Ivanov, his first play (1887) was a failure; his second, The Seagull (1896), was ridiculed in St Petersburg. Later, the New Moscow Arts Theatre successfully produced The Seagull, Uncle Vanya (1899), Three Sisters (1901) and his genius was finally confirmed with The Cherry Orchard (1903).

Biographers focus on two medical exploits. Shortly after qualifying he decided to visit a penal colony at Sakhalin in Siberia, undertaking a long and arduous journey on foot, by cart and boat. He produced a comprehensive report of the island, its inhabitants and their multitude of illnesses, based on appalling and inhumane living conditions. After publication, governmental censorship swiftly quashed any further comment or corrective action. Similarly, despite the suggestion to the University of Moscow that Chekhov's labours were worthy of academic recognition, none was bestowed. Two years later, in his first year in Melikhovo he was made superintendent of services to counteract a fierce outbreak of cholera.

Like so many great artists and writers of his era, he fell victim to tuberculosis, and is said to have first coughed up blood on his 25th birthday. Doubtless the hardships of his expedition to Sakhalin aggravated his symptoms. He tried numerous remedies, alas in vain. He died in Bedenweile in 1904, attempting the "cure". Chekhov was one of those fascinating characters who left Medicine and achieved fame and distinction in other ventures; Lord Moynihan called them "Medical Truants." 